The authors use their broad backgrounds in science policy, history and English literature to locate the question of body ownership within the wider fields of social science and bioethics. Their primary argument is that developments in biocommerce are best understood within the emergence of the 'information society'. Body parts and tissues, such as gene sequences and cell lines, become information products that are mobilized and gain value in the wider tissue economy.

Most importantly, the authors make the point that the tensions this creates - in terms of who should have the right to own tissue is not specific to nor created by the advent of biotechnology. Instead, debates over ownership rights are endemic to an industrial society where knowledge and information are allowed to take on a commodifiable form, as in a patent. This is nicely captured in the case of John Moore, in which it is observed that "Moore couldn't own the cell line [because] research would stop - but if no one owned the cell line, research would also stop". The authors explain how each case study reveals a particular aspect of the information society.

Any bioethicist would struggle to find principles that might act as an arbiter of the moral dilemmas posed by the different cases in Biofutures. Indeed, the authors steer clear of this, concluding that we need to attain a deeper understanding. There is not one biofuture but many, articulated in both dystopian and utopian images. Futures are traded as expectations that shape markets for biotech products - so the future itself becomes commodified, not just its body parts.

Andrew Webster is professor of the sociology of science at the University of York, Heslington, York Y010 5DD, UK, and author of Health, Technology and Society: A Sociological Critique. e-mail:ajw25@york.ac.uk

\title{
Primed for evolution
}

\author{
Why Evolution is True \\ by Jerry A. Coyne \\ Oxford Univ. Press/Viking Press: 2009. \\ 336 pp/304 pp. $€ 14.99 / \$ 27.95$
}

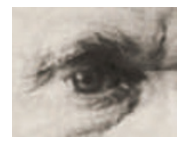

Jerry Coyne, an accomplished population geneticist at the University of Chicago in Illinois, has devoted much time Darwin200 recently to attacking creationism. His articles in popular publications neatly dissect the scientific claims of the creationists, clearly showing their logical and empirical failings. In Why Evolution is True, he shifts his concerns to demonstrate to an open-minded reader the strength of evolutionary biology. The book is one long argument for why the theory so often associated with Charles Darwin should - as much as any other well-founded scientific explanation - be recognized as true.

Writing in a conversational yet authoritative tone, Coyne makes evolutionary biology accessible. As befits his speciality, he stresses the genetic foundations of natural selection and adaptation, offering examples from the field and laboratory for how natural selection shapes morphology and biochemistry to adapt species to their environments. Attention is devoted in this balanced book not only to genes and molecules, but also to the fossil record, sexual selection and biogeography. The patterns of distribution of plants and animals over geographic areas provided a key clue to
Darwin, and Coyne gives this finding its due. Speciation is the missing link in the general public's understanding of evolution, so it is good to see it discussed early in the book and developed fully in a later chapter. Simple natural selection - microbes becoming resistant to antibiotics, weeds developing resistance to pesticides - is not objectionable to evolution sceptics. What they object to is the tree of life - evolution's core concept of common

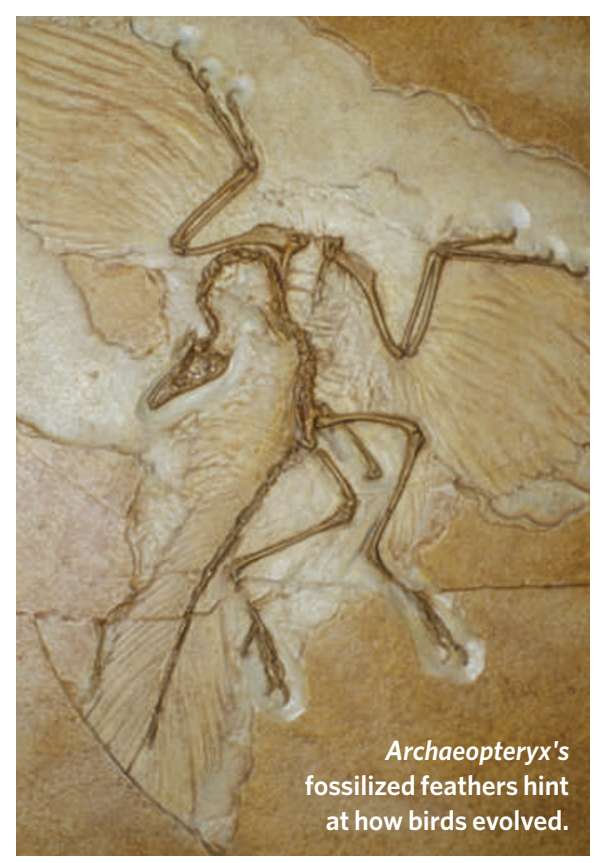

ancestry. How can very different animals such as bats and humans be related? Coyne clarifies the basics of geographic speciation and its importance to evolution: it produces lineages that are initially similar, which then diverge through successive speciation events. Given billions of years of lineage splitting and extinction, the result is bats, humans and everything else on Earth.

Also useful is Coyne's distinction between ancestors and transitional fossils - a common source of confusion. Transitions are exhibited by fossils such as Archaeopteryx, which has both dinosaur and bird traits, and the deer-like Indohyus, which has traits of both even-toed hoofed mammals and whales, but such fossils may occur at the wrong time or have the wrong suite of features to be ancestral to modern forms. Given the nature of the fossil record, Coyne explains, we would not expect to find or identify ancestral fossils, but we can find cousin species that share transitional features with the elusive direct ancestors. Transitional features therefore delineate how the tree of life branches. Unfortunately, Coyne never quite defines ancestral and derived traits, which would help to clarify the discussion.

A book for the public must simplify, but there lurks the possibility of subsequent distortion. Many people misunderstand evolution as a great chain in which simple forms evolve into more complex ones, rather than the branching and extinction of lineages. Amphibians did not evolve into reptiles, and reptiles did not evolve into mammals and birds. Rather, a population of early tetrapods - four-legged vertebrates - gave rise to a diverse group of organisms that included ancestors of modern frogs and salamanders, and to a separate branch characterized by having an amniotic egg. A primitive amniote gave rise to reptiles and birds on one branch, and mammals on another. Given that the branch leading to mammals preceded that leading to reptiles, it is misleading for Coyne to use the outmoded term 'mammal-like reptiles' instead of 'non-mammalian synapsids'.

It remains a dismal truth that in the United States, almost half of the population does not accept the common ancestry of humans and chimpanzees; anti-evolution sentiments are also manifest in the rest of the developed world, albeit less virulently. Coyne's book will be a good choice to give to the neighbour or teacher who wants to know more about evolutionary biology. Lamentably, his book is still needed.

Eugenie Scott is executive director of the National Center for Science Education, Oakland, California 94609, USA, and author of Evolution vs. Creationism.

e-mail:scott@ncseweb.org 